\title{
Open-field $\Delta$-ambulation as a selection tool for bidirectional responses in maze learning in Mus musculus L.
}

\author{
S. BÉATRICE M. EWALDS-KVIST and RITVA-KAJSA SELANDER \\ Åbo Akademi University, Turku, Finland
}

and

\author{
MÅRTEN O. R. KVIST \\ University of Turku, Turku, Finland
}

\begin{abstract}
This paper presents the results of a bidirectional selective breeding experiment involving 1,287 mice. It was conducted by means of $\Delta$-ambulation - that is, by summing positive and negative learningassociated alterations in open-field ambulation over a 5-day period of training. $\Delta$-ambulation remained constant, but a selection response was found in maze running times and error scores over generations and sexes in the two diverging, intralinearly homogenous, strains of mice.
\end{abstract}

In this paper, we report the first bidirectional selective breeding experiment by means of $\Delta$-ambulation (i.e., the summed average day-to-day acquisition-associated positive and negative alterations in open-field [OF] ambulation) conducted and administered on two lines of mice. This experiment served to illuminate the complex relationship between OF activity and spatial learning. Previously, the acquisition of a new stimulating task has been thought to be positively reflected in enhanced, measurable, overt movements in phylogenetically low organisms, such as rodents (K. Y. H. Lagerspetz, Tirri, \& K. M. J. Lagerspetz, 1968). Thus, only increased motor activation pertaining to learning was, as a rule, reported. For example, Mitani, Ando, and Nagata (1972) trained white rats on a foodreinforced runway. The experienced rats enhanced their activity level in a running wheel relative to their untrained counterparts. Furthermore, Milkovic, Paunovic, and Joffe (1976) observed that OF activity was increased by prior avoidance conditioning. The possibility that a new acquisition experience modifies the motor activity bidirectionally was touched on in an experiment concerning the impact of familiarity with the environment when interindividual variations were noted in learning-induced ambulation (Kvist, 1983; K. Y. H. Lagerspetz, Kvist, \& K. M. J. Lagerspetz, 1980). This notion was further supported by an OF-ambulation experiment conducted in conjunction with maze learning and passive-avoidance conditioning on outbred Swiss albino and NMRI mice and on inbred Balb/c, C3H/He, C57BL/6J, and DBA/2N animals. The outbred Swiss albino and NMRI mice reacted similarly to the inbred Balb/c animals, and hybrids of these

Correspondence should be addressed to S.B.M. Ewalds-Kvist, Department of Psychology, Åbo Akademi University, FIN-20500 Turku, Finland (e-mail: bekvist@abo.fi). strains reacted in the form of a positive OF activity response as opposed to that of, for example, C57BL/6J, which exhibited a negative learning-related motor discharge (Kvist, 1984). The training-modified motor responses of the hybrids (Swiss albino $\times$ NMRI; Swiss albino $\times \mathrm{Balb} / \mathrm{c}$ ) suggested that there was a genetic basis for changing one's motor activity in relation to the mastering of a new task.

It is important in this context to give an account of a few classical experiments on rodents concerning OF activity and maze learning. First, Tuttle and Dykshorn (1929) combined learning with motor activity and discovered a strong positive relationship between revolvingcage activity and improved spatial learning in a circular maze in rats. Tryon (1940/1967) then successfully established a two-way selection for brigthness and dullness with regard to T-maze learning in rats. DeFries, Wilson, and McClearn (1970) selected from hybrids of inbred $(\mathrm{Balb} / \mathrm{cJ} \times \mathrm{C} 57 \mathrm{BL} / 6 \mathrm{~J})$ lines of mice for high and low OF activity. Nevertheless, Streng (1974) related mice selected for high and low OF activity to wheel-turn avoidance conditioning and the mastering of a Lashley III maze, and this study did not lend support to there being a simple correlation between learning and OF activity. Kvist (1985) systematically studied increased OF ambulation after several types of learning. Kvist's series of experiments gave the impetus to establish a unidirectionally selectively bred line for maze-learning-related increased $O F$ ambulation (Kvist \& Selander, 1990). Generation 6 of the selection was found to be superior in maze learning and in exhibiting an increased posttraining OF ambulation, relative to that of the unselected Swiss albino control mice.

By focusing on the relationship between maze learning and $\mathrm{OF}$ ambulation, the present study recognized the reciprocity, or interaction, between the two elements continuously determining each other throughout the experi- 
mentation. The logical conclusion was that if one of two cooperating factors - learning or OF ambulation - remained stable over more than 10 generations, the expression of a selection response would be expected in the other. The aim of the present work was to verify this hypothesis.

\section{METHOD}

\section{Subjects}

A bidirectional selective breeding experiment on maze-learningmodified OF ambulation was initiated in July of 1988. The selected 12 generations are all descendants of a Swiss albino stock, which was normally distributed $(\mathrm{N})$ with regard to $\mathrm{OF}$ ambulation. The outbred N stock originated from Malmö, Sweden (K. M. J. Lagerspetz, 1964). The two selected lines were named Increase Open Field Turku (IOFT) and Decrease Open Field Turku (DOFT). Altogether, 1,287 mice were used. The parental generation $(P)$ comprised $23 \mathrm{~N}$ females with an initial ambulatory activity score of $M=25.5(S D=13.5)$; for the $25 \mathrm{~N}$ males, the score was $M=35.1$ $(S D=16.0)$. IOFT was composed of 331 females and 326 males, and DOFT was composed of 292 females and 310 males. All mice were bred and reared in the laboratory of the Department of Psychology at Åbo Akademi University. The animals were weaned at the age of 4 weeks before they reached sexual maturity. The mice participated in the experiment from the age of approximately 4 months when they were weighed and introduced to both the OF device and the maze device. On average, IOFT females weighed $25.1 \mathrm{~g}(S D=$ $0.6)$, and IOFT males weighed $31.9 \mathrm{~g}(S D=0.9)$; DOFT females weighed $25.5 \mathrm{~g}(S D=0.6)$, and males weighed $32.0 \mathrm{~g}(S D=1.1)$. At the age of approximately 4.5 months, the animals were mated within lines. Average $\Delta$-ambulation, number of successful matings, and litter sizes are presented in Table 1.

\section{Housing Conditions}

The mice were individually housed on the day before the beginning of the experiment. The wire-topped laboratory aluminum cages measured $12.0 \times 15.5 \times 15.5 \mathrm{~cm}$ and were equipped with a sawdust bedding unchanged during the period of experimentation. The mice were maintained in an air-conditioned noiseless breeding room on a 12:12-h light:dark cycle, with artificial lights on at 7:00 a.m. The room temperature was approximately $22^{\circ} \mathrm{C}$, and the humidity was $45 \%$. Standard laboratory animal food pellets (R3, Lactamin, Sweden) and tap water were available ad lib. During maze learning, pellets were diurnally restricted to $3 \mathrm{~g}$ per mouse (i.e., approximately $10 \%$ of the animal's body weight; Kvist, 1985, p. 30 ) in the home cage. The test recordings were performed by the same experimenter from 7:00 to 10:00 a.m. or 5:00 to 8:00 p.m. for each generation in an adjacent experimental room under conditions identical to those of the breeding room.

\section{Apparatus}

The OF consisted of a circular, flat, white, wooden arena $(40 \mathrm{~cm}$ in diameter) with a $20-\mathrm{cm}$-high wall of flat, white iron plating. The field was marked with thin black lines to delineate three concentric circles, which were in turn divided by 12 lines radiating from the center. The floor was thereby subdivided into a total of 19 partitions (Figure 1). The track of the animal was marked on an identically divided map to provide raw scores for calculation of ambulation or wall-seeking behavior (Kvist \& Selander, 1992a, 1992b). The arena was cleaned with a wet paper towel and dried with another paper towel between successive recordings, which is considered an adequate

Table 1

Number, Average $\Delta$-Ambulation, Percentage of Successful Matings, and Average Litter Sizes of Parental (P) and Selected (S1-S11) IOFT and DOFT Female and Male Mice

\begin{tabular}{|c|c|c|c|c|c|c|}
\hline \multirow[b]{2}{*}{ Selection } & \multirow{2}{*}{$\begin{array}{l}\text { Number of } \\
\text { Females }\end{array}$} & \multirow{2}{*}{$\begin{array}{l}\text { Number of } \\
\text { Males }\end{array}$} & \multicolumn{2}{|c|}{ Ambulation } & \multirow{2}{*}{$\begin{array}{c}\text { Successful } \\
\text { Matings (\%) }\end{array}$} & \multirow[b]{2}{*}{ Litter Size } \\
\hline & & & Female & Male & & \\
\hline \multicolumn{7}{|c|}{ IOFT } \\
\hline $\mathbf{P}$ & 10 & 6 & 5.2 & 9.2 & 100 & 6.2 \\
\hline S1 & 10 & 10 & 5.4 & 7.4 & 80 & 6.9 \\
\hline $\mathrm{S} 2$ & 10 & 10 & 2.5 & 5.2 & 90 & 7.0 \\
\hline S3 & 10 & 10 & 6.8 & 11.6 & 80 & 8.4 \\
\hline S4 & 10 & 10 & 5.4 & 5.9 & 100 & 7.1 \\
\hline S5 & 10 & 10 & 3.6 & 5.2 & 90 & 6.8 \\
\hline S6 & 10 & 10 & 7.3 & 10.5 & 90 & 7.3 \\
\hline S7 & 10 & 10 & 7.7 & 12.0 & 80 & 8.3 \\
\hline S8 & 9 & 9 & 4.1 & 5.2 & 100 & 6.1 \\
\hline S9 & 8 & 8 & 4.9 & 4.5 & 100 & 4.4 \\
\hline $\mathrm{S} 10$ & 8 & 8 & 5.7 & 6.6 & 100 & 5.0 \\
\hline S11 & 5 & 5 & -2.0 & 3.4 & 100 & 8.8 \\
\hline \multicolumn{7}{|c|}{ DOFT } \\
\hline$P$ & 11 & 11 & -12.3 & -13.6 & 82 & 7.1 \\
\hline S1 & 10 & 10 & -5.8 & -2.5 & 90 & 7.6 \\
\hline S2 & 10 & 10 & -5.3 & -6.7 & 70 & 8.1 \\
\hline S3 & 10 & 10 & -12.5 & -13.5 & 80 & 7.5 \\
\hline S4 & 10 & 10 & -14.5 & -9.6 & 70 & 7.4 \\
\hline S5 & 10 & 10 & -8.0 & -8.6 & 100 & 7.5 \\
\hline S6 & 10 & 10 & -6.8 & -5.6 & 90 & 7.0 \\
\hline S7 & 10 & 10 & -10.6 & -9.4 & 100 & 6.4 \\
\hline S8 & 10 & 10 & -8.7 & -9.4 & 100 & 6.7 \\
\hline S9 & 8 & 8 & -8.2 & -9.5 & 25 & 0.8 \\
\hline S10 & 4 & 1 & & & 100 & 6.0 \\
\hline S11 & 8 & 8 & -3.4 & -3.5 & 88 & 4.6 \\
\hline
\end{tabular}




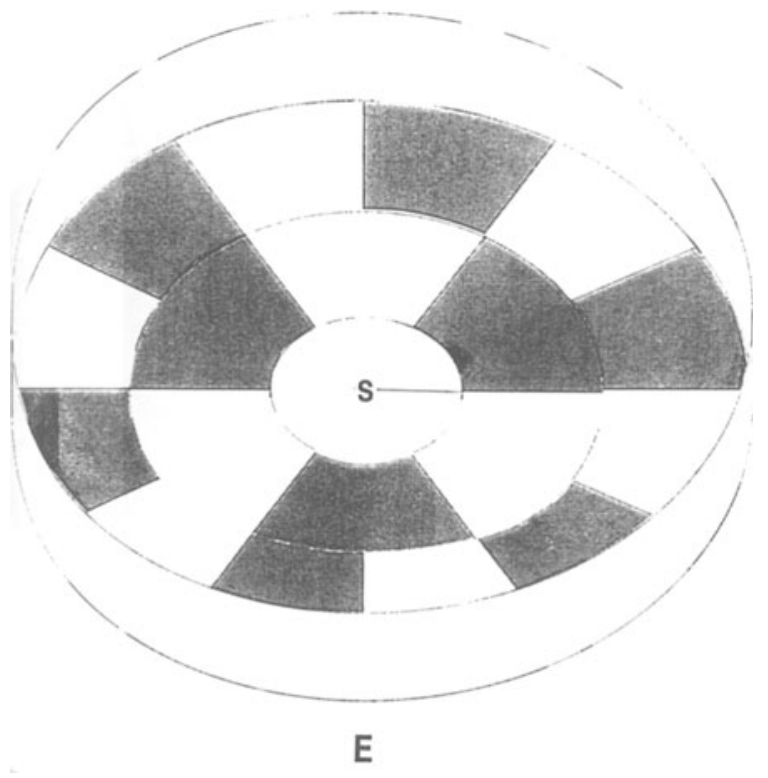

Figure 1. Circular open field subdivided into a total of 19 partitions. Starting point (S) of the mouse and position of the experimenter (E) are depicted.

method to prevent the subjects from following the odors left by other animals (K. M. J. Lagerspetz, 1964, p. 87). The reliability of the ambulation scores in the OF is .69 (K. M. J. Lagerspetz, 1964).

The maze consisted of a simple, uncovered linear device made of unpainted galvanized iron plating. The maze measured $157 \mathrm{~cm}$ in length, $22 \mathrm{~cm}$ in width, and $18 \mathrm{~cm}$ in height. The apparatus was composed of L-shaped detachable partitions, which created blind alleys providing 11 choosing points, or possibilities for errors, from the entrance to the goalbox $(13 \times 13 \times 18 \mathrm{~cm})$. The maze was brushed after each trial and frequently douched with warm water (Kvist, 1983; K. M. J. Lagerspetz, 1964).

\section{Procedure}

Selection process. The mice were selected on the basis of their average difference in ambulatory activity ( $\Delta$-ambulation) as measured before and after learning for a training period of 5 days. A period of 5 days is considered to be the minimum period for the acquisition of a linear maze (Kvist, 1985) and a sufficient period for recording reliable OF ambulatory activity (Whimbey \& Denenberg, 1967). Thus, each of the females was once in estrous during the time of experimentation (Kvist \& Selander, 1994). Mice exhibiting highly positive $\Delta$-ambulation and mice displaying the most negative $\Delta$-ambulation were mated within their respective lines. Thus, two homogenous, although diverging, lines as regards positive (IOFT) and negative (DOFT) ambulation were selected. The $\Delta$-ambulations of the mice chosen as parents for the 12 generations are presented in Table 1 .

Quantitative open-field motor activity. The term ambulation, or locomotion, denotes unprovoked motor activity in the form of spontaneous whole body movements from one OF unit to another. The mouse always started from the center OF unit with its tail directed toward the experimenter. The animal's track was recorded when moving from one floor unit to another over a 2-min period (Figure 1). Each visited unit was registered as a score on a similarly divided map. Thus, each mouse received its individual sum of scores both immediately before and approximately 25 min after maze learning.

Qualitative open-field motor activity. The term thigmotactic wall seeking signifies ambulatory orientation toward the OF periph- eral units but does not necessarily imply bodily contact with the $\mathrm{OF}$ wall. Seven center partitions delineated the two inner circles, and 12 OF units depicted the peripheral circle (Figure 1). The thigmotactic ratio- the orientation toward the periphery of the $\mathrm{OF}$ - was derived from the number of inner partitions entered divided by the sum of units visited by the animal. Hence, the greater the ratio, the more

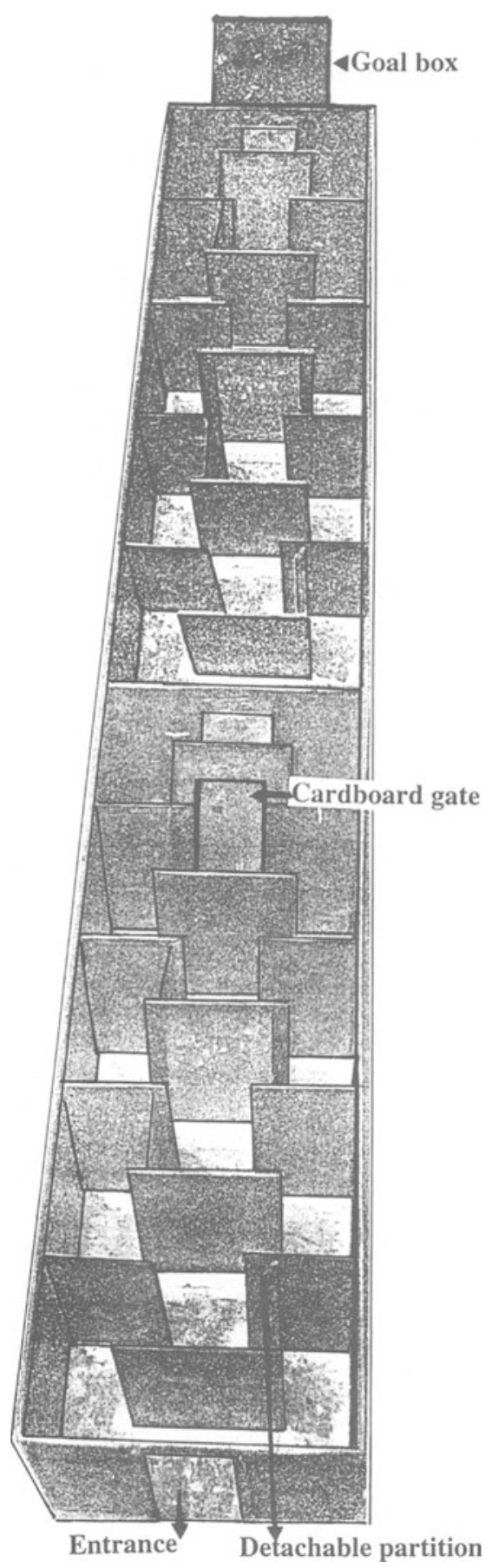

Figure 2. A linear 11-point uncovered maze made of galvanized iron plating $(157 \times 22 \times 18 \mathrm{~cm})$. The path of the maze was manually blocked with a cardboard gate $(8 \times 0.2 \times 18 \mathrm{~cm})$ in order to prevent the mouse from retracing its track. 

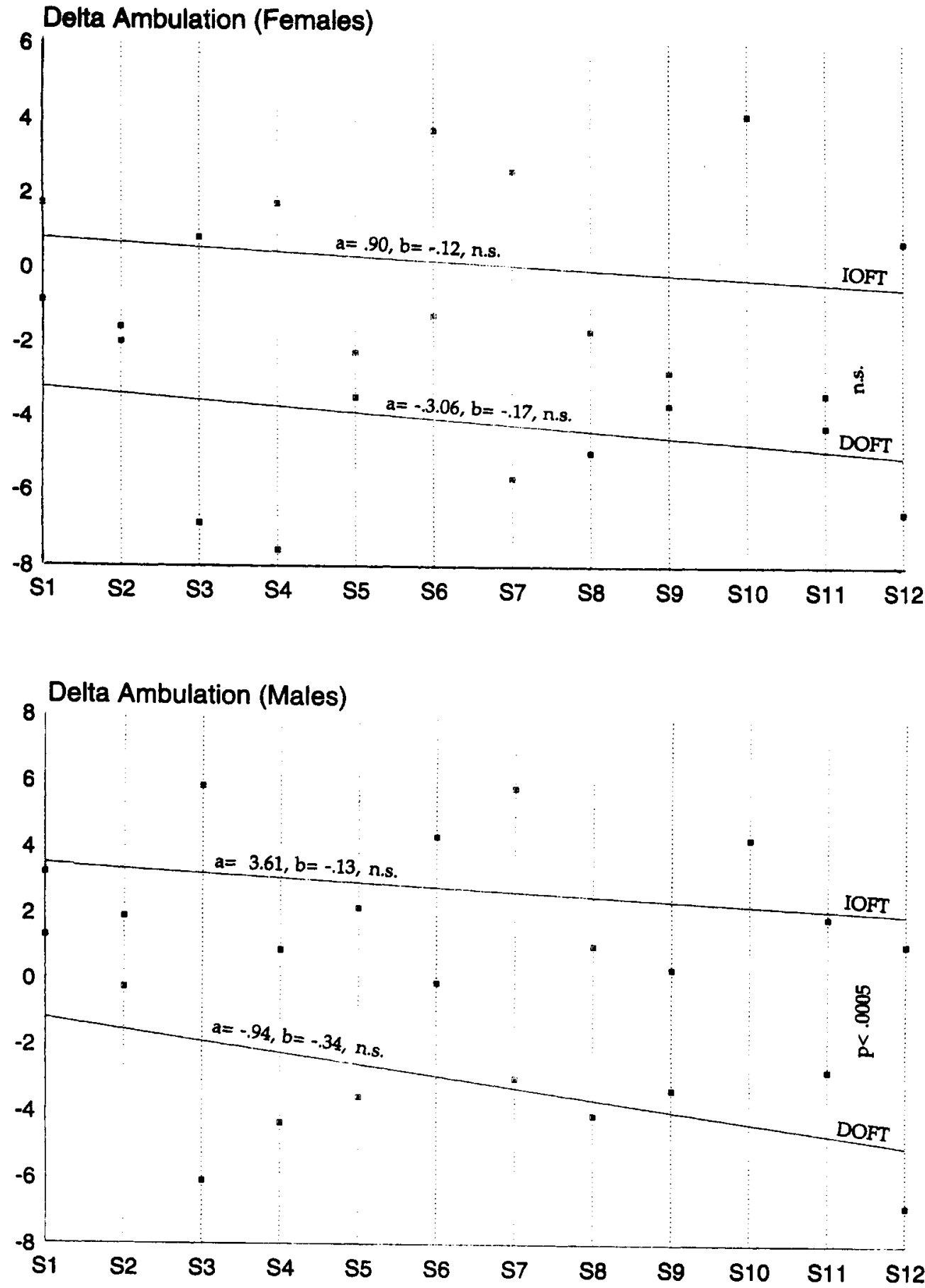

Figure 3. Linear regression curves for $\Delta$-ambulation of IOFT and DOFT of both sexes. The levels of significance $(p)$ of the regression coefficients are presented, as are the values of intercept $(a)$ and slope $(b)$.

prone the mouse was to remain in the inner OF area (Kvist \& Selander, 1992a, 1992b).

Maze learning. The mice ran the maze once a day for 5 successive days. The running times (in seconds) and error scores (i.e., the sum of entrances to blind alleys) were recorded from the entrance gate to the goalbox where standard laboratory food pellets were available ad lib for approximately $5 \mathrm{~min}$. The maze path was blocked with a cardboard gate after each visit into a blind alley to prevent the animal from retracing its track. After training, the mouse was transferred to a glass container $(3 \mathrm{l})$, where the animal was allowed access to an unlimited food supply for $20 \mathrm{~min}$ (Figure 2).

To sum up, the daily testing of each mouse was as follows: 2 min OF ambulation $\rightarrow$ maze trial $\rightarrow 5$ min reward in the goal box $\rightarrow$ 20 min unlimited food supply in a glass container $\rightarrow 2 \mathrm{~min}$ OF ambulation. Each of these events followed in succession. 
Table 2

Significant ANOVA Results From 12 Selected Generations of IOFT Mice in the Maze and the Open Field

\begin{tabular}{|c|c|c|c|c|}
\hline \multirow[b]{2}{*}{ Day } & \multicolumn{2}{|c|}{ Female } & \multicolumn{2}{|c|}{ Male } \\
\hline & $F$ & $p$ & $F$ & $p$ \\
\hline \multicolumn{5}{|c|}{ Running Time } \\
\hline 1 & 7.38 & .000 & 6.34 & .000 \\
\hline 2 & 2.77 & .002 & 5.38 & .000 \\
\hline 3 & & & 2.97 & .001 \\
\hline 4 & 5.78 & .000 & 3.67 & .000 \\
\hline 5 & 4.64 & .000 & 4.39 & .000 \\
\hline \multicolumn{5}{|c|}{ Error Score } \\
\hline 1 & 4.68 & .000 & 3.68 & .000 \\
\hline 2 & 3.42 & .000 & 5.00 & .000 \\
\hline 3 & 4.75 & .000 & 3.83 & .000 \\
\hline 4 & 11.62 & .000 & 5.44 & .000 \\
\hline 5 & 5.68 & .000 & 4.92 & .000 \\
\hline \multicolumn{5}{|c|}{ Ambulation Before Maze Learning } \\
\hline 1 & 5.73 & .000 & 4.45 & .000 \\
\hline 2 & 1.86 & .044 & 2.59 & .004 \\
\hline 3 & 2.11 & .020 & 3.94 & .000 \\
\hline 4 & 2.43 & .007 & 3.35 & .000 \\
\hline 5 & 4.25 & .000 & 1.88 & .042 \\
\hline \multicolumn{5}{|c|}{ Ambulation After Maze Learning } \\
\hline 1 & 4.48 & .000 & 5.21 & .000 \\
\hline 2 & 2.17 & .016 & 2.50 & .005 \\
\hline 3 & & & 3.20 & .000 \\
\hline 4 & 3.72 & .000 & 4.47 & .000 \\
\hline 5 & 2.53 & .005 & 3.62 & .000 \\
\hline \multicolumn{5}{|c|}{ Thigmotaxis Before Maze Learning } \\
\hline 1 & 3.12 & .001 & 3.86 & .000 \\
\hline 3 & 3.25 & .001 & & \\
\hline 5 & 1.97 & .044 & & \\
\hline \multicolumn{5}{|c|}{ Thigmotaxis After Maze Learning } \\
\hline 4 & & & 2.07 & .033 \\
\hline 5 & 2.30 & .017 & 3.32 & .001 \\
\hline
\end{tabular}

Note-Females, $n=331$; males, $n=326$.

Statistics. Analyses of variance (ANOVAs) and $t$ tests were computed by means of BMDP7D (1990, Statistical Software, Inc.). Regression analyses were computed by means of Wistat (1990).

\section{RESULTS}

\section{Accomplished Breeding}

The results of the IOFT and DOFT animals of both sexes (selected for continuation on the basis of their most positive or negative $\Delta$-ambulation scores) of the two lines are shown in Table 1. Furthermore, Table 1 indicates that both selected lines displayed a normal average litter size (Kvist, Selander, \& Viemerö, 1995): IOFT gave birth to 6.92 pups $(S D=1.36)$, and DOFT gave birth to 6.33 pups $(S D=2.07)$, with an acceptable level of successful matings with the exception of selection 9 DOFT animals.

\section{Quantitative Open-Field Motor Activity}

Delta ambulation linear regression curves in association with the maze learning of both sexes of the IOFT and DOFT lines are depicted in Figure 3 . The regression coefficients of the slopes comprising S1 to S12 generations are nonsignificant-that is, the $\Delta$-ambulation neither increased nor decreased over selections. However, for the males, the average $\Delta$-ambulation of IOFT was significantly $(p<.0005)$ variant from that of DOFT. The results of the learning-related ambulation were analyzed in detail between each of the 5 experimental days, although the mice were selected on the basis of their average summed difference or $\Delta$-ambulation as measured before and after learning (Table 1). The significant results of the daily difference between generations computed by means of an ANOVA are presented in Tables 2 and 3. As a general rule, significant daily differences were found with regard to ambulation before and after maze learning between the 12 selections. The IOFT females were the exceptions rather than the rule: Regardless of generation, they displayed a similar pattern of ambulation after maze learning on the 3rd day of experimentation (Table 2). With regard to DOFT animals (Table 3 ), the females diverged between selections before learning on Experimental Days 2 to 5 and after learning on the 1st day. On the other

Table 3

Significant ANOVA Results From 12 Selected Generations of DOFT Mice in the Maze and the Open Field

\begin{tabular}{|c|c|c|c|c|}
\hline \multirow[b]{2}{*}{ Day } & \multicolumn{2}{|c|}{ Female } & \multicolumn{2}{|c|}{ Male } \\
\hline & $F$ & $p$ & $F$ & $p$ \\
\hline \multicolumn{5}{|c|}{ Running Time } \\
\hline 1 & 10.64 & .000 & 28.52 & .000 \\
\hline 2 & 4.44 & .000 & 8.47 & .000 \\
\hline 3 & & & 7.95 & .000 \\
\hline 4 & & & 4.75 & .000 \\
\hline 5 & & & 3.94 & .000 \\
\hline \multicolumn{5}{|c|}{ Error Score } \\
\hline 1 & 3.02 & .001 & & \\
\hline 2 & 2.55 & .006 & 3.83 & .000 \\
\hline 3 & 2.59 & .005 & 4.04 & .000 \\
\hline 4 & 1.96 & .037 & 6.15 & .000 \\
\hline 5 & & & 5.97 & .000 \\
\hline \multicolumn{5}{|c|}{ Ambulation Before Maze Learning } \\
\hline 1 & & & 6.10 & .000 \\
\hline 2 & 2.40 & .010 & 4.95 & .000 \\
\hline 3 & 3.48 & .000 & 7.20 & .000 \\
\hline 4 & 3.78 & .000 & 5.90 & .000 \\
\hline 5 & 4.64 & .000 & 8.34 & .000 \\
\hline \multicolumn{5}{|c|}{ Ambulation After Maze Learning } \\
\hline 1 & 2.38 & .010 & 3.33 & .000 \\
\hline 2 & & & 2.70 & .003 \\
\hline 3 & & & 2.89 & .002 \\
\hline 4 & & & 2.43 & .008 \\
\hline 5 & & & 3.06 & .001 \\
\hline \multicolumn{5}{|c|}{ Thigmotaxis Before Maze Learning } \\
\hline 1 & 6.62 & .000 & 5.96 & .000 \\
\hline 2 & 2.50 & .014 & & \\
\hline 3 & & & 2.94 & .006 \\
\hline 4 & & & 2.21 & .034 \\
\hline 5 & & & 2.76 & .009 \\
\hline \multicolumn{5}{|c|}{ Thigmotaxis After Maze Learning } \\
\hline 1 & 2.46 & .019 & 2.59 & .014 \\
\hline 5 & & & 2.20 & .035 \\
\hline
\end{tabular}

Note-Females, $n=292$; males, $n=310$. 
Table 4

Daily Average Maze-Learning and Open-Field Recordings of Behavior Displayed by IOFT Mice of Selections S1, S6, and S12

\begin{tabular}{|c|c|c|c|c|c|c|c|c|c|c|c|c|}
\hline \multirow[b]{3}{*}{ Day } & \multicolumn{4}{|c|}{ S1 } & \multicolumn{4}{|c|}{ S6 } & \multicolumn{4}{|c|}{$\mathrm{S} 12$} \\
\hline & \multicolumn{2}{|c|}{ Female } & \multicolumn{2}{|c|}{ Male } & \multicolumn{2}{|c|}{ Female } & \multicolumn{2}{|c|}{ Male } & \multicolumn{2}{|c|}{ Female } & \multicolumn{2}{|c|}{ Male } \\
\hline & Avg. & $S E$ & Avg. & $S E$ & Avg. & $S E$ & Avg. & $S E$ & Avg. & $S E$ & Avg. & $S E$ \\
\hline \multicolumn{13}{|c|}{ Running Time } \\
\hline 1 & 66.5 & 3.4 & 66.1 & 4.1 & 51.2 & 1.8 & 49.7 & 1.8 & 56.9 & 2.7 & 53.0 & 2.4 \\
\hline 2 & 48.3 & 4.0 & 49.5 & 2.8 & 43.5 & 1.2 & 41.3 & 1.3 & 43.6 & 2.0 & 42.8 & 1.9 \\
\hline 3 & 37.8 & 3.4 & 38.9 & 2.3 & 35.5 & 1.3 & 35.6 & 1.6 & 38.6 & 2.0 & 38.3 & 1.1 \\
\hline 4 & 33.6 & 2.7 & 33.1 & 2.0 & 34.1 & 1.4 & 31.5 & 1.5 & 39.1 & 1.6 & 37.2 & 1.3 \\
\hline 5 & 28.3 & 1.7 & 28.2 & 1.9 & 28.1 & 1.4 & 25.0 & 1.2 & 34.8 & 1.9 & 32.5 & 1.2 \\
\hline \multicolumn{13}{|c|}{ Error Score } \\
\hline 1 & 3.5 & 0.3 & 3.9 & 0.4 & 6.6 & 0.5 & 5.4 & 0.4 & 6.5 & 0.5 & 6.3 & 0.5 \\
\hline 2 & 3.2 & 0.4 & 3.1 & 0.3 & 5.5 & 0.4 & 5.2 & 0.4 & 5.5 & 0.6 & 5.4 & 0.4 \\
\hline 3 & 2.4 & 0.3 & 2.7 & 0.4 & 4.5 & 0.3 & 4.0 & 0.3 & 5.3 & 0.4 & 5.0 & 0.3 \\
\hline 4 & 2.5 & 0.4 & 2.2 & 0.2 & 3.7 & 0.3 & 3.5 & 0.3 & 6.6 & 0.4 & 5.3 & 0.4 \\
\hline 5 & 2.1 & 0.3 & 1.6 & 0.2 & 2.7 & 0.2 & 2.5 & 0.2 & 4.8 & 0.4 & 3.3 & 0.3 \\
\hline \multicolumn{13}{|c|}{ Ambulation Before Maze Learning } \\
\hline 1 & 13.1 & 1.6 & 12.6 & 1.4 & 18.4 & 2.0 & 12.7 & 1.4 & 20.1 & 2.5 & 22.3 & 2.8 \\
\hline 2 & 11.8 & 1.8 & 11.8 & 1.9 & 9.0 & 1.3 & 11.0 & 2.1 & 11.6 & 1.4 & 14.7 & 2.4 \\
\hline 3 & 12.4 & 1.6 & 13.4 & 1.8 & 10.5 & 1.7 & 10.8 & 1.8 & 14.8 & 1.8 & 11.3 & 1.7 \\
\hline 4 & 11.6 & 1.3 & 14.2 & 2.1 & 13.4 & 2.0 & 14.5 & 2.4 & 10.7 & 1.2 & 11.7 & 1.5 \\
\hline 5 & 13.2 & 1.9 & 12.2 & 2.1 & 17.8 & 2.3 & 17.7 & 2.2 & 11.7 & 1.8 & 14.0 & 1.5 \\
\hline \multicolumn{13}{|c|}{ Ambulation After Maze Learning } \\
\hline 1 & 18.5 & 2.0 & 20.5 & 2.1 & 19.1 & 2.5 & 17.6 & 2.0 & 13.0 & 2.3 & 16.8 & 2.8 \\
\hline 2 & 13.6 & 1.9 & 13.3 & 1.8 & 13.1 & 1.3 & 13.6 & 1.7 & 13.1 & 2.6 & 13.7 & 2.4 \\
\hline 3 & 13.1 & 1.4 & 13.6 & 1.6 & 15.3 & 2.4 & 17.6 & 1.9 & 15.0 & 2.9 & 15.2 & 1.6 \\
\hline 4 & 12.5 & 1.2 & 16.1 & 1.7 & 18.8 & 2.2 & 18.1 & 2.2 & 15.5 & 2.4 & 17.9 & 2.0 \\
\hline 5 & 13.4 & 1.6 & 14.3 & 1.5 & 19.5 & 2.3 & 21.5 & 2.2 & 15.7 & 2.6 & 17.4 & 1.4 \\
\hline \multicolumn{13}{|c|}{ Thigmotaxis Before Maze Learning } \\
\hline 1 & .36 & .05 & .38 & .04 & .26 & .04 & .32 & .04 & .39 & .04 & .33 & .05 \\
\hline 2 & .19 & .03 & .23 & .04 & .29 & .05 & .23 & .04 & .21 & .03 & .31 & .03 \\
\hline 3 & .18 & .03 & .23 & .05 & .25 & .03 & .28 & .04 & .29 & .05 & .31 & .04 \\
\hline 4 & .24 & .03 & .20 & .03 & .27 & .05 & .29 & .04 & .32 & .06 & .32 & .05 \\
\hline 5 & .27 & .04 & .35 & .05 & .29 & .03 & .26 & .03 & .34 & .04 & .29 & .03 \\
\hline \multicolumn{13}{|c|}{ Thigmotaxis After Maze Learning } \\
\hline 1 & .23 & .04 & .25 & .04 & .27 & .04 & .27 & .04 & .36 & .05 & .38 & .03 \\
\hline 2 & .26 & .03 & .26 & .03 & .24 & .03 & .27 & .04 & .42 & .06 & .35 & .03 \\
\hline 3 & .30 & .04 & .24 & .03 & .28 & .04 & .30 & .04 & .43 & .06 & .26 & .04 \\
\hline 4 & .34 & .04 & .32 & .04 & .32 & .04 & .36 & .04 & .30 & .04 & .34 & .03 \\
\hline 5 & .44 & .04 & .45 & .05 & .39 & .05 & .39 & .04 & .33 & .04 & .32 & .03 \\
\hline
\end{tabular}

hand, DOFT males always conformed to the rule and differed between the 12 selections in their learning-related ambulation.

\section{Qualitative Open-Field Motor Activity}

Wall-seeking behavior, or thigmotaxis, exhibited by IOFT and DOFT animals before and after maze learning was analyzed by means of an ANOVA for each of the 5 experimental days (see Tables 2, 3, 4, and 5). Before the learning session, the IOFT females differed between generations on Days 1, 3, and 5, in contrast to the IOFT males, who diverged only the 1 st day of experimentation. After maze learning, the IOFT females varied on the last day, but the IOFT males varied on Days 4 and 5 (Table 2). With regard to DOFT animals, the females differed be- fore learning between selections on the $1 \mathrm{st}$ and 2 nd days and after maze training on the 1 st day. The DOFT males varied between selections before learning on Days 1, 3, 4 , and 5 , as well as after maze training on the 1 st and the last day (Tables 2, 3, 4, and 5). Thus, the wall-seeking behavior displayed by lines and sexes in conjunction with maze learning did not conform to any general rule.

\section{Maze Learning}

The change of behavior during maze learning exhibited by both sexes of the IOFT and DOFT lines from S1 to $\mathrm{S} 12$ was recorded in the forms of running times and error scores per generation. Linear regression curves for these two measures of maze learning were computed for the 1 st and the last day of training, which yielded a dif- 
Table 5

Daily Average Maze-Learning and Open-Field Recordings of Behavior Displayed by DOFT Mice of Selections S1, S6, and S12

\begin{tabular}{|c|c|c|c|c|c|c|c|c|c|c|c|c|}
\hline \multirow[b]{3}{*}{ Day } & \multicolumn{4}{|c|}{ S1 } & \multicolumn{4}{|c|}{ S6 } & \multicolumn{4}{|c|}{$\mathrm{S} 12$} \\
\hline & \multicolumn{2}{|c|}{ Female } & \multicolumn{2}{|c|}{ Male } & \multicolumn{2}{|c|}{ Female } & \multicolumn{2}{|c|}{ Male } & \multicolumn{2}{|c|}{ Female } & \multicolumn{2}{|c|}{ Male } \\
\hline & Avg. & $S E$ & Avg. & $S E$ & Avg. & $S E$ & Avg. & $S E$ & Avg. & $S E$ & Avg. & $S E$ \\
\hline \multicolumn{13}{|c|}{ Running Time } \\
\hline 1 & 69.6 & 3.7 & 81.9 & 2.5 & 59.8 & 1.7 & 58.8 & 1.4 & 43.6 & 1.2 & 41.7 & 1.9 \\
\hline 2 & 48.6 & 4.3 & 62.6 & 4.0 & 48.6 & 1.6 & 51.0 & 1.6 & 36.7 & 1.7 & 37.1 & 1.6 \\
\hline 3 & 37.9 & 3.4 & 55.7 & 4.3 & 42.0 & 1.9 & 43.4 & 1.4 & 32.2 & 1.7 & 31.7 & 1.5 \\
\hline 4 & 31.6 & 2.7 & 44.9 & 3.8 & 37.0 & 2.4 & 37.1 & 1.4 & 32.1 & 2.1 & 30.7 & 1.1 \\
\hline 5 & 28.0 & 2.1 & 35.7 & 2.5 & 31.5 & 1.5 & 31.9 & 1.3 & 31.8 & 2.0 & 29.3 & 1.4 \\
\hline \multicolumn{13}{|c|}{ Error Score } \\
\hline 1 & 5.1 & 0.5 & 5.2 & 0.4 & 5.7 & 0.4 & 5.7 & 0.3 & 4.8 & 0.3 & 5.1 & 0.3 \\
\hline 2 & 3.6 & 0.4 & 3.4 & 0.3 & 5.1 & 0.3 & 4.8 & 0.3 & 4.0 & 0.4 & 4.3 & 0.4 \\
\hline 3 & 3.2 & 0.4 & 3.2 & 0.3 & 4.7 & 0.3 & 4.8 & 0.2 & 4.1 & 0.4 & 3.1 & 0.4 \\
\hline 4 & 3.1 & 0.4 & 2.7 & 0.3 & 4.3 & 0.4 & 4.2 & 0.2 & 3.7 & 0.4 & 3.7 & 0.3 \\
\hline 5 & 3.0 & 0.4 & 2.4 & 0.3 & 3.7 & 0.3 & 3.9 & 0.3 & 3.9 & 0.4 & 3.1 & 0.4 \\
\hline \multicolumn{13}{|c|}{ Ambulation Before Maze Learning } \\
\hline 1 & 21.6 & 3.1 & 13.5 & 1.9 & 22.0 & 2.7 & 20.6 & 1.6 & 8.8 & 3.6 & 36.7 & 4.3 \\
\hline 2 & 18.4 & 2.2 & 14.2 & 2. & 13 & & 12.7 & & 2 & & 29.6 & 4.3 \\
\hline 3 & 12.5 & 1.6 & 10.6 & 1.7 & 11 & & 11.8 & 1.2 & 17.6 & & 29.3 & 4.6 \\
\hline 4 & 13.3 & 1.7 & 11.3 & 1.6 & 13 & 1. & 15.8 & 2.0 & 21.8 & 4.1 & 28.9 & 3.8 \\
\hline 5 & 12.0 & 1.5 & 11.6 & 1.1 & 17.7 & 2.2 & 21.5 & 2.6 & 19.7 & 2.6 & 20.6 & 3.4 \\
\hline \multicolumn{13}{|c|}{ Ambulation After Maze Learning } \\
\hline 1 & 20.9 & 1.7 & 17.6 & 2.0 & 14.3 & 1.6 & 17.3 & 1.7 & 14.0 & 2.3 & 28.4 & 4.5 \\
\hline 2 & 13.7 & 1.9 & 13.0 & 1.7 & 10.7 & 1.4 & 12.3 & 1.2 & 10.2 & 2.9 & 19.3 & 4.1 \\
\hline 3 & 13.2 & 1.7 & 11.1 & 1.7 & 12.7 & 1.6 & 15.8 & 1.7 & 12.5 & 2.4 & 23.6 & 4.2 \\
\hline 4 & 12.5 & 1.5 & 12.9 & 1.2 & 14.4 & 1.7 & 15.7 & 1.5 & 12.5 & 2.6 & 21.1 & 3.9 \\
\hline 5 & 12.4 & 1.4 & 12.5 & 1.4 & 17.5 & 2.1 & 20.9 & 2.6 & 16.7 & 2.6 & 18.8 & 3.1 \\
\hline
\end{tabular}

Thigmotaxis Before Maze Learning

$\begin{array}{lllllllllllll}1 & .26 & .03 & .34 & .04 & .29 & .04 & .42 & .04 & .22 & .03 & .28 & .03 \\ 2 & .20 & .03 & .20 & .03 & .29 & .04 & .30 & .04 & .22 & .05 & .25 & .03 \\ 3 & .22 & .03 & .22 & .04 & .31 & .04 & .34 & .04 & .33 & .05 & .27 & .04 \\ 4 & .21 & .03 & .26 & .04 & .31 & .04 & .33 & .04 & .26 & .04 & .23 & .05 \\ 5 & .24 & .03 & .29 & .03 & .33 & .05 & .41 & .04 & .23 & .03 & .31 & .04\end{array}$

Thigmotaxis After Maze Learning

\begin{tabular}{lllllllllllll}
1 & .24 & .04 & .33 & .04 & .29 & .03 & .34 & .04 & .29 & .05 & .31 & .03 \\
2 & .27 & .03 & .25 & .03 & .27 & .04 & .34 & .05 & .36 & .05 & .35 & .05 \\
3 & .23 & .03 & .29 & .04 & .37 & .04 & .35 & .04 & .26 & .03 & .36 & .06 \\
4 & .33 & .04 & .34 & .03 & .38 & .05 & .36 & .04 & .34 & .04 & .27 & .05 \\
5 & .39 & .04 & .48 & .05 & .47 & .05 & .44 & .04 & .35 & .05 & .34 & .06 \\
\hline
\end{tabular}

Note - S1 females, $n=33$; S1 males, $n=30$. S6 females, $n=35$; S6 males, $n=40$. S12 females, $n=21$; S12 males, $n=16$.

ference between the 2 days always at the same level of significance ( $p<.0005$; see Figures 4 and 5$)$. The IOFT females and males ran the maze significantly faster but accumulated more error scores over generations on Day 1. On Day 5, a curve similar to that of Day 1, with regard to error scores, was displayed by the IOFT females (Figure 4). Accordingly, both DOFT females and males of S12 ran the maze faster on Day 1 than the animals of S1. Both sexes of the DOFT line, however, accumulated more error scores over generations on the last day of experimentation (Figure 5).

\section{DISCUSSION}

Daily learning-related activity increases have previously been observed after several types of learning
(K. Y. H. Lagerspetz et al., 1980). However, a learningrelated activity decrease was also observed in an experiment designed to examine whether this phenomenon occurs independently of the environment or results only from the stimulation of novel cues (Kvist, 1983). Furthermore, it has previously been established that the activation of motor responses per se was not enough to cause the same amount of motor activation as a learning task did (Kvist, 1985, p. 87). Also the possibility that an OFactivity increase generated by the learning process had a hereditary basis was addressed in an experiment aimed at assessing the extent to which this kind of activity enhancement could be generalized from Swiss albino to other strains of mice (Kvist, 1984). Accordingly, a unidirectional selection experiment was successfully conducted and reported (Kvist \& Selander, 1990). Conse- 
IOFT (Fomeles)

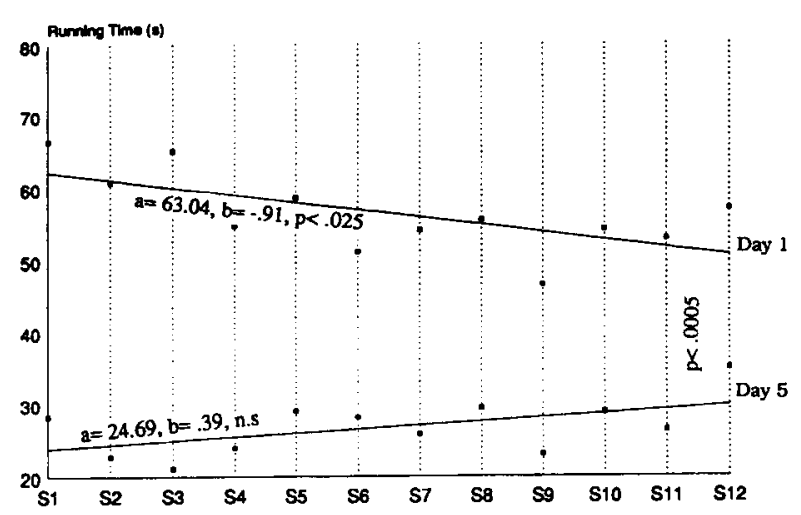

IOFT (Females)

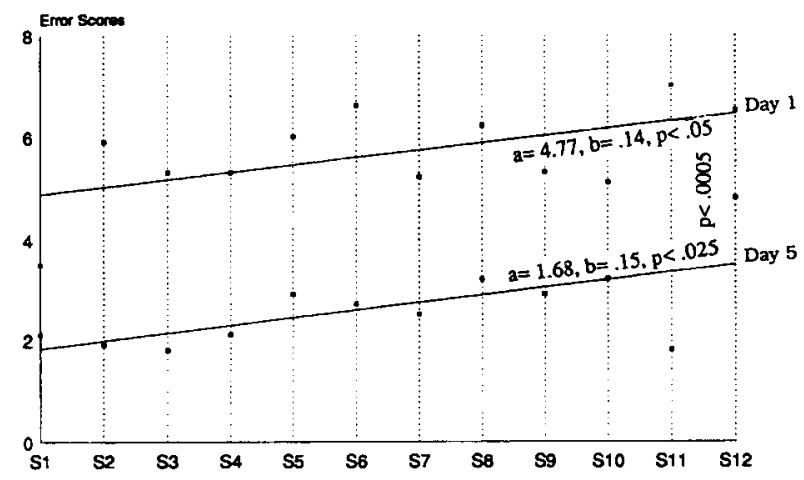

IOFT (Males)

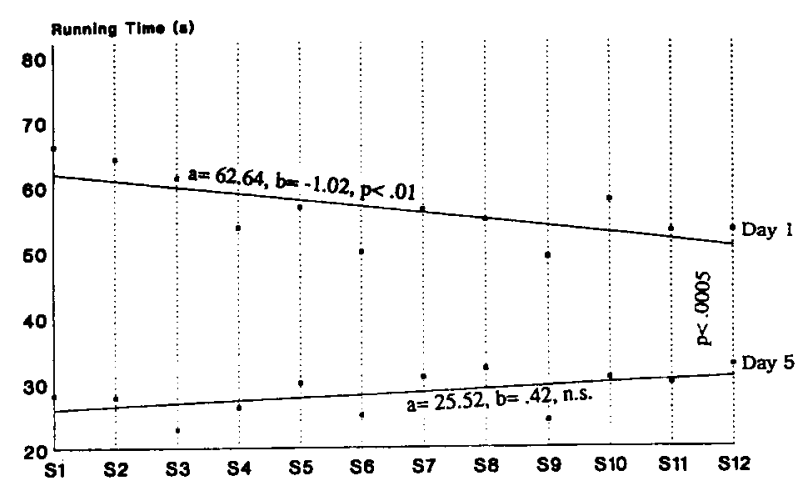

IOFT (Males)

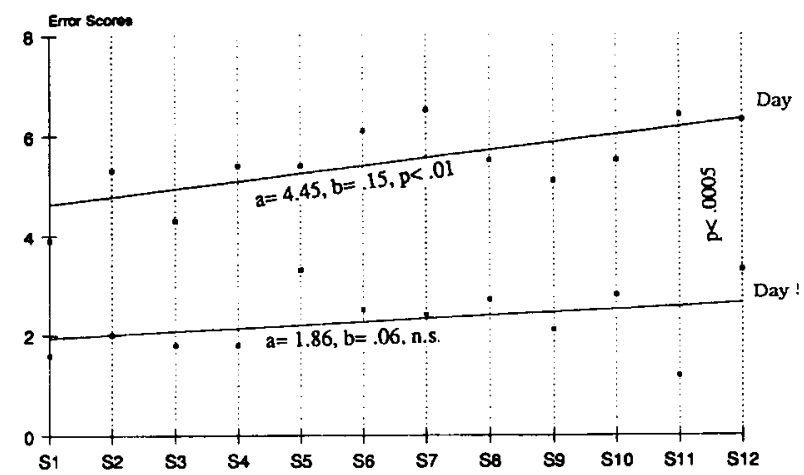

Figure 4. The maze-learning running times and error scores for IOFT females and males as a selection response expressed in a linear regression curve with levels of significance $(p)$ of the regression coefficients. Values of intercept $(a)$ and slope $(b)$ are presented.

quently, it remained to be proved whether this type of selection experiment could be conducted bidirectionally. The results of such a bidirectional selection are presented in this paper.

According to Ulbrich and Palmer (1996), each animal exhibits a range of individual strategies in an experimental situation every day. Until now, only day-to-day learningrelated alterations in activity from small samples of rodents have been reported (Kvist, 1985; Milkovic et al., 1976; Mitani et al., 1972). However, it is possible to minimize the intraindividual variation by abandoning the day-to-day recordings in favor of aggregating data across experimental days. In general, aggregation can reduce error variance associated with the unrepresentativeness of individual stimuli, situations, and subjects. It enhances the reliability and validity while establishing the range of generality of a phenomenon by means of averaging over many measurements (Epstein, 1983). Aggregation enhances the reliability of scores in the OF test (Tachibana, 1985). The relationship between learning and quantitative motor activity - in the form of maze-learning necessitating spatial ability, as well as OF-ambulation, call- ing for an animal's whole body movements - was thus investigated in a more reliable way. In other words, the present artificial selection procedure was conducted on the basis of the new measure, OF $\Delta$-ambulation, comprising the average summed day-to-day variations in learning-related motor activity to counterbalance extreme values between experimental days. Daily nonaggregated inter- and intraanimal variations in ambulation in conjunction with learning lead to the false conclusion of there being a lack of conformity to a rule with regard to a selection response that can be translated into testable predictions about an interaction between learning and motor activity.

The range of the calculated $\Delta$-ambulation in the kuge sample of mice at hand was maintained over sex, generation, and strain. Two homogenous lines were thus established with regard to positive (IOFT) and negative (DOFT) $\Delta$-ambulation in males. Females tended to display similar, but nonsignificant, $\Delta$-ambulation linear regression curves; the latter outcome may at least in part be explained by their estrous cycles or metabolism (Ewalds-Kvist, Selander, \& Sandnabba, 1997; Kvist \& Selander, 1994). Female 

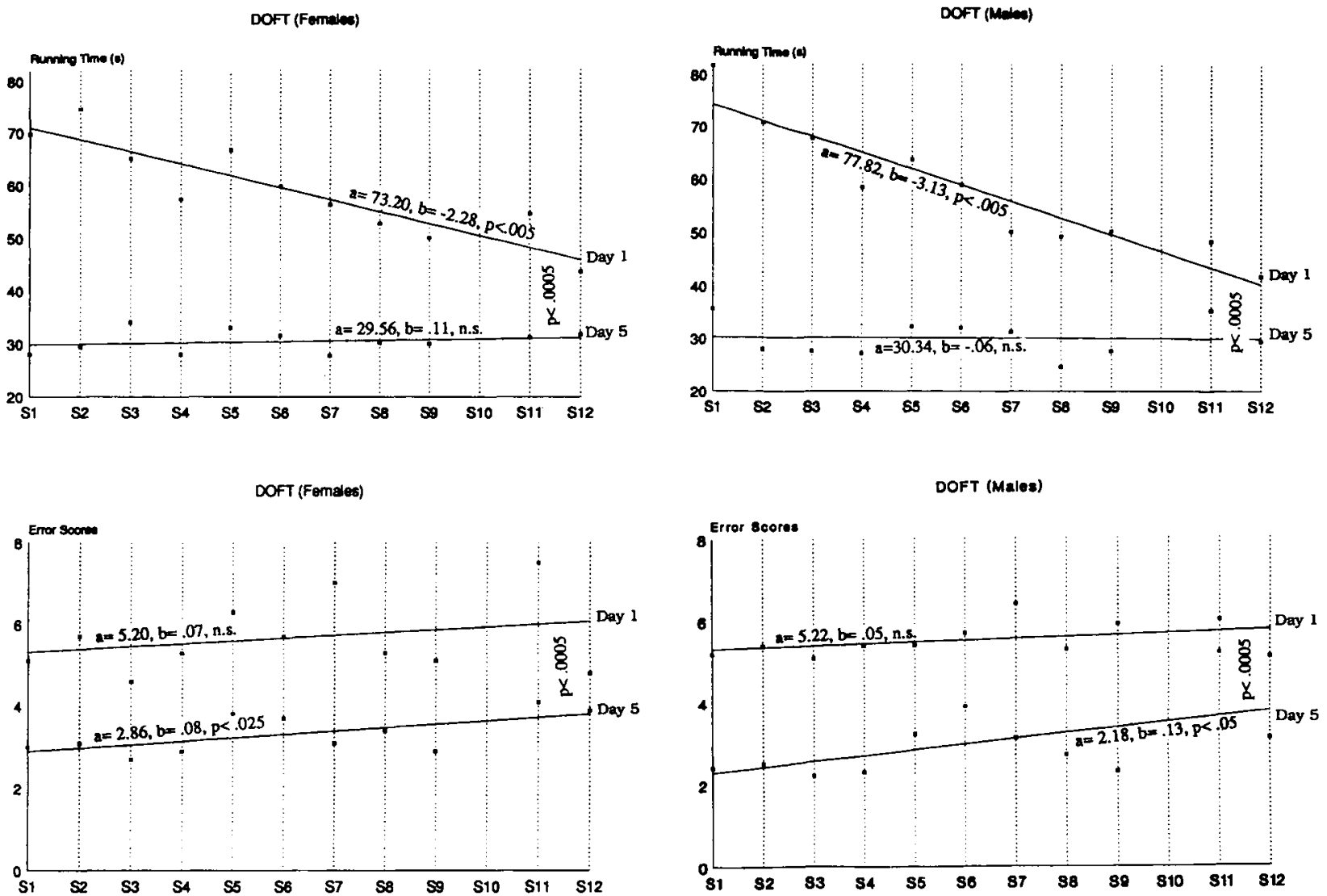

Figure 5. Linear regression curves for maze-learning running times and error scores for DOFT mice of both sexes. The levels of significance $(p)$ of the regression coefficients are presented, as are the values of intercept $(a)$ and slope $(b)$.

mice are known to be less reliable experimental animals in research on motor activity; hence, researchers are reluctant to use them (e.g., Kvist, 1985; Kvist \& Selander, 1987).

It was hypothesized that if one of the two reciprocal variables remains stable over several generations, it would be expected that a selection response would be expressed in the other parameter (cf. Strijbosch, Does, \& Albers, 1990). In other words, the $\Delta$-ambulation was stable, and the maze learning varied. A response of heredity with reference to maze running time was most obvious during the 1 st experimental day, as depicted in linear regression curves, the slopes of which are all significant over sex, generation, and strain. By the completion of the experimental period (Day 5), the results of the maze running were considered to be a product of the training process per se. This response of heredity appears to be stronger in DOFT males than in those of IOFT, as depicted in the form of a steeper linear regression curve of their 1 st day running time; the DOFT males, on the other hand, accumulated more error scores. This fact suggests the possibility that increased maze speed can lead to an increase in the number of error scores or to the conclusion that IOFT males are brighter than DOFT animals with regard to their spatial ability. The latter speculation has to be verified by means of several types of learning tasks (cf. K. Y. H. Lagerspetz et al., 1980).

With regard to daily qualitative OF motor activity, Kvist and Selander (1992a) previously indicated by means of factor analysis that maze-learning-related OF wall-seeking behavior loaded on two factors, which they called spontaneous and learning-related thigmotaxis; the latter type of wall seeking expresses itself first after three or four trials out of five after mastering a spatial task (Kvist \& Selander, 1992b). IOFT males, as opposed to those of the DOFT line, displayed a learning-related thigmotaxis homogenously over several generations, which supports the idea that these males are more susceptible to the effects of this type of learning. In agreement with summed daily measures of learning-related quantitative motor activity $(\Delta$-ambulation), a corresponding day-to-day qualitative measure is unacceptable as a tool for selective breeding unless the data are aggregated and transformed into a spontaneous and a learning-related $\Delta$-measure of thigmotaxis.

In conclusion, the following hypothesis was confirmed: If one of two cooperating elements-OF activity or learning - remains stable over generations, the expression of a selection response is to be expected in the other. Accordingly, by means of the new selection tool, $\Delta$-ambulation, 
two intralinearly homogenous strains, diverging with regard to maze learning, were successfully established. The present results strengthen the relationship between learning and activity and will contribute to the resolution of the debate on the existence of such a relationship.

\section{REFERENCES}

DeFries, J. C., Wilson, J. R., \& McClearn, G. E. (1970). Open-field behavior in mice: Selection response and situational generality. $B e$ havior Genetics, 1, 195-211.

EPSTEIN, S. (1983). Aggregation and beyond: Some basic issues on the prediction of behavior. Journal of Personality, 51, 360-392.

Ewalds-Kvist, S. B. M., Selander, R.-K., \& Sandnabba, N. K. (1997). Sex-related coping responses in mice selectively bred for aggression. Perceptual \& Motor Skills, 84, 911-914.

KvIST, [S.] B. [M.] (1983). Open field activity after learning in mice. Scandinavian Journal of Psychology, 24, 313-324.

KvisT, [S.] B. [M.] (1984). Strain differences in open field activity after learning in mice. Scandinavian Journal of Psychology, 25, 370-380.

KVIST, [S.] B. [M.] (1985). Open field activity after learning in mice (Rep. from the Department of Psychology at Åbo Akademi, Monograph Suppl. 2, pp. 1-128). Turku, Finland: Ábo Akademis Kopieringscentral.

Kvist, S. B. M., \& SElander, R.-K. (1987). Sex difference in open field activity after learning in mice. Scandinavian Journal of Psychology, 28, 88-91.

Kvist, S. B. M., \& Selander, R.-K. (1990). Mice selectively bred for an open field activity increase after maze learning. Scandinavian Journal of Psychology, 30, 128-138.

KVIST, S. B. M., \& SELANDER, R.-K. (1992a). Maze-running and thigmotaxis in mice: Applicability of models across the sexes. Scandinavian Journal of Psychology, 33, 378-384.

Kvist, S. B. M., \& SElAnder, R.-K. (1992b). Qualitative aspects of learning-sensitive open field ambulation in mice. Scandinavian Journal of Psychology, 33, 97-107.

Kvist, S. B. M., \& Selander, R.-K. (1994). Open-field thigmotaxis during various phases of the reproductive cycle. Scandinavian Journal of Psychology, 35, 220-229.

Kvist, S. B. M., Selander, R.-K., \& Viemerö, V. (1995). The impact of newborn on adult mice: Open-field behavior along with pullus index. Psychobiology, 23, 214-223.
LAGERSPETZ, K. M. J. (1964). Studies on the aggressive behaviour of mice (Suomalaisen Tiedeakatemian Toimituksia. Annales Academiae Scientarium Fennicaes: Series B, Vol. 131, pp. 1-131). Helsinki: Suomalainen Tiedeakatemia.

LAGerspetZ, K. Y. H., Kvist, [S.] B. [M.], \& LAGERSPETZ, K. M. J. (1980). Several types of learning increase open-field activity in mice. Scandinavian Journal of Psychology, 21, 215-222.

LagersPetZ, K. Y. H., ThrRI, R., \& LagersPeTZ, K. M. J. (1968). Neurochemical and endocrinological studies of mice selectively bred for aggressiveness. Scandinavian Journal of Psychology, 9, 157-160.

Milkovic, K., Paunovic, J., \& Joffe, J. M. (1976). Effects of pre- and postnatal litter size reduction on development and behavior of rat offspring. Developmental Psychobiology, 9, 365-375.

Mitani, K., Ando, M., \& Nagata, H. (1972). An enhancement of general activity through a particular learning experience in white rat. The Annual of Animal Psychology, 22, 21-27.

STRENG, J. (1974). Exploration and learning behavior in mice selectively bred for high and low levels of activity. Behavior Genetics, 4 191-204.

Strijbosch, L. W., Does, R. J., \& Albers, W. (1990). Design methods for dose-response models. Statistical Medicine, 9, 1353-1363.

TACHIBANA, T. (1985). Higher reliability and closer relationship between open-field test measures on aggregation data. Animal Learning \& Behavior, 13, 345-348.

TRYON, R. C. (1967). Genetic differences in maze-learning ability in rats. In A. Anastasi (Ed.), Individual differences (pp. 138-148). New York: Wiley. (Original work published 1940)

TutTle, W. W., \& DYKshoRN, S. (1929). A comparison of spontaneous activity of the albino rat with ability to learn, with special reference to the effect of castration and ovariectomy on these processes. Physiological Zoology, 11, 157-167.

Ulbrich, B., \& Palmer, A. K. (1996). Neurobehavioral aspects of developmental toxicity testing. Enviromental Health Perspectives, 104, 407-412.

Whimbey, A. E., \& Denenberg, V. H. (1967). Two independent behavioral dimensions in open field performance. Journal of Comparative \& Physiological Psychology, 63, 500-504.

WISTAT [Statistical computer programs] (1990). Åbo Academi University, Department of Statistics.

(Manuscript received November 6, 1997; revision accepted for publication October 23,1998 .) 